\title{
Price Rigidity in Customer Markets
}

Elke Renner and Jean-Robert Tyran

September 2003 D iscussion Paper no. 2003-16 
Editor: $\quad$ Prof. Jörg Baumberger

University of St. G allen

Department of Economics

Bodanstr. 1

$\mathrm{CH}-9000$ St. Gallen

Phone +41712242241

Fax $\quad+41712242885$

Publisher: $\quad$ Forschungsgemeinschaft für $\mathrm{N}$ ationalökonomie

Email_joerg.baumberger@ unisg.ch an der Universität St. Gallen

D ufourstrasse 48

$\mathrm{CH}-9000$ St. Gallen

Phone $\quad+41712242300$

Fax $\quad+41712242646$

Electronic Publication:

www.fgn.unisg.ch/public/public.htm 


\title{
Price Rigidity in Customer Markets
}

\author{
Elke Renner and Jean-Robert Tyran ${ }^{1}$
}

Authors' addresses:

\author{
Dr. Jean-Robert Tyran \\ Department of Economics \\ Bodanstr. 1 \\ $\mathrm{CH}-9000$ St. Gallen \\ Tel. $\quad$ +41712315 \\ Fax $\quad+41712816$ \\ Email Lean-Robert.Tyran@ unisg.ch \\ W ebsite http://www.vwa.unisg.ch/tyran/ \\ Dipl-Vw. Elke Renner \\ Lehrstuhl für Mikroökonomie \\ University Erfurt \\ N ordhäuser Str. 63 \\ D - 99089 Erfurt \\ Email elke.renner@uni-erfurt.de
}

\footnotetext{
${ }^{1}$ W e thank seminar participants at the Radcliffe Institute (Harvard), the Max Planck Institute (Jena), at the Universities of Heidelberg, Mainz, Marburg and Strasbourg, Simon G ächter, Bettina Rockenbach, and Julio Rotemberg for helpful comments. W e are grateful for financial support by the University of Erfurt and the GFF-foundation for basic research (University of St. Gallen) under project no. G02110108.
} 


\begin{abstract}
Customer markets are characterized by long-term relations between buyers and sellers. Long-term relations evolve if buyers trust sellers to provide high quality and if sellers are trustworthy. However, changes in the terms of this implicit contract may antagonize customers and disrupt the relation. We experimentally show that mutually beneficial long-term relations frequently prevail in markets for experience goods, and that price rigidity after a temporary cost shock is much more pronounced if price increases cannot be justified by cost increases. Hence, long-term relations on customer markets mitigate market failure of the "lemons" type, but are prone to price stickiness.
\end{abstract}

\title{
Keywords
}

Customer market, price stickiness, customer loyalty

\section{JEL Classification}

C 92, D 43, L14, Z13. 


\section{Introduction}

The intuition that implicit contracts between buyers and sellers are an important source of price rigidity has been eloquently developed by Arthur Okun (1981). Okun coined the term "customer markets" for markets with long-term relations between buyers and sellers. On customer markets, he argued, sellers may be reluctant to increase prices in response to temporary cost shocks because changes in the terms of the implicit contract may antagonize customers and disrupt the customer relation. Okun also speculated that customers may be less antagonized if price increases can be justified by increases in sellers' costs. Hence, according to this intuition, long-term relations on customer markets are a source of price rigidity, but price rigidity is less pronounced if price increases can be justified by cost increases.

Despite the importance of price rigidity in macroeconomics and industrial organization, relatively little was known about the empirical validity of Okun's intuitions until recently (see Carlton 1989 or Wynne 1995 for surveys). This lack of empirical knowledge is surprising since customer markets are of utmost economic importance. According to Blinder et al. (1998, p.302), "about 85 percent of all the goods and services in the U.S. nonfarm business sector are sold to "regular customers " with whom sellers have an ongoing relationship". The reason why relatively little was known is that most theories of price stickiness rely on variables that are either unobservable by conventional methods or unobserved in practice. Hence, "the abject failure of the standard research methodology to make headway on this critical issue in the microfoundations of macroeconomics" (Blinder et al., p. 3) motivated researchers in recent years to use "unorthodox approaches" to investigate the issue of price rigidity in customer markets.

Empirical evidence on the relevance of Okun's intuitions comes from questionnaire and experimental studies. In a much-cited questionnaire study, Kahneman, Knetsch and Thaler 
(1986) have investigated fairness perceptions of price increases in the general public. They find that people perceive price increases to be more acceptable if they can be justified by cost increases. However, their findings also suggest that price rigidity does not depend on whether buyers and sellers have a one-time or a long-term relation. In a compelling interview study Blinder et al. evaluate motives for pricing decisions from the perspective of the sellers. Systematic interviews with managers who are responsible for pricing decisions show that long-term relations are common and important, and that managers are careful not to antagonize their customers by their pricing decisions. The authors find support for the notion that managers believe customers to be less antagonized when price increases can be justified by cost increases. Much to their surprise, they do not find that price rigidity is related to longterm relations. In a similar interview study with Swedish firms, Apel, Friberg and Hallsten (2001) find that implicit contracts are the most important explanation for price rigidity.

Experimental evidence usefully complements findings from questionnaire studies because market interaction can be observed in controlled environments. Cason and Friedman (2002) study price rigidity in an opaque market in which buyers develop customer relations to save on search costs. The authors show that higher search costs tend to induce customers to remain with their seller which, in turn, increases the sellers' market power and induces considerable price rigidity. However, the authors do not investigate the hypothesis that price rigidity is less pronounced if price increases can be justified by cost increases. The relevance of this hypothesis is investigated in a series of three closely related papers (Kachelmeier, Limberg and Schadewald 1991a, 1991b, Franciosi et al. 1995). These papers find weak and non-persistent price rigidity when price increases cannot be justified by cost increases. However, these studies do not analyze customer markets because long-term relations are excluded by design in these experiments. It is important to note that all experimental studies 
cited above analyze markets for "inspection goods". In such markets, no quality uncertainty prevails.

Our experimental study is the first to investigate long-term relations on markets for experience goods as an explanation of price rigidity. For experience goods, quality uncertainty prevails in the sense that buyers learn the quality of the good only after the purchase. The reason why we analyze markets for experience goods is our focus on how trust in customer relations generates price rigidity. We believe that trust is an important factor shaping customer markets in addition to saving on search costs in an opaque market. In fact, Okun (p. 141) noted that "the extent to which firms are likely to enjoy repeat patronage depends both on the satisfaction of customers with previous purchases and their confidence that the supplier will maintain good performance." Hence, long-term customer relations may be upheld if buyers trust sellers to provide high quality and if sellers are trustworthy.

We compare behavior in two experimental markets which differ with respect to whether buyers and sellers can develop long-term relations. Both markets are opaque in the sense that market outcomes cannot be publicly observed, and on both markets quality uncertainty prevails. High quality is more valuable to buyers, but its provision is more costly to sellers. In the "customer market", buyers can trade repeatedly with the same seller and can thus develop long-term trading relations. In contrast, this is not possible on the "anonymous market" where buyers and sellers do not know whom they trade with. In this market, economic theory predicts the "lemon outcome" (Akerlof 1970). That is, low quality is provided at low prices because sellers cannot build a relation-specific reputation by providing high quality. In contrast, in the "customer market", upholding customer relations by providing high quality at a reasonable price may also be profitable to sellers if this induces customers to return to this seller. 
To analyze whether customer relations are upheld and whether they partially resolve the "lemons" problem, we compare the anonymous market and the customer market. To analyze whether the customer market causes price rigidity, we compare price adjustment in response to a cost shock in the two markets. To analyze the "cost justification" hypothesis of price rigidity, we compare price adjustment in two customer markets which exclusively differ with respect to the information about the cost shock. In one treatment, buyers are informed about the cost shock (i.e., information is public), and in the other treatment they are not (i.e., information is private to sellers). Hence, with public information a price increase is "justified" by a cost increase, while with private information it is not.

Our main results are as follows. First, we find that long-term customer relations are frequently upheld, and that average quality is about three times higher when customer relations are possible. Higher quality on the customer market comes at a higher price, but upholding the relation is profitable for both sellers and buyers on average. Hence, we find that customer relations partially resolve the lemons problem. Second, we show that price rigidity is more pronounced on the customer market than on the anonymous market after a temporary cost shock. We show that customers tend to penalize sellers for price increases and, in particular, for providing low quality by terminating the customer relation. Third, we show that price rigidity is more pronounced if the price increase cannot be justified by a cost increase. In this case, sellers increase prices much less, and bear considerable losses to avoid antagonizing customers. In all, we show that customer markets mitigate the "lemons" problem but are prone to price stickiness. Since long-term customer relations are upheld in our customer market because buyers trust sellers to provide high quality, this paper also demonstrates how trust can shape market outcomes. 
We proceed as follows. Section 2 explains the advantages of an experimental approach to price rigidity in customer markets, and relates this study to the literature. Section 3 explains the experimental design, section 4 presents the experimental results, and section 5 concludes.

\section{An experimental approach to price rigidity in customer markets}

We test three hypotheses about to how trust shapes customer markets. Our first hypothesis $\mathrm{H} 1$ is that customer markets resolve the "lemons" problem. This hypothesis has already casually been suggested in the seminal article by Akerlof (see also Arrow 1973). That is, we test whether buyers trust sellers to deliver higher quality in a customer market than in an anonymous market. ${ }^{1}$ We expect this hypothesis to hold because two previous experimental studies have found that long-term relations endogenously form in markets with quality uncertainty, and that they improve on market performance. Kollock (1994) obtains these findings by comparing markets with and without quality uncertainty and private vs. public offers. Brown, Falk and Fehr (2002) investigate a gift exchange labor market in which buyers (firms) choose prices, and sellers (workers) choose the quality (effort). They compare two markets which differ with respect to the anonymity of market participants. They find that long-term relations are upheld in non-anonymous markets, and that these relations are mutually beneficial. However, both studies analyze stable environments, and do, therefore, not investigate whether long-term relations cause price rigidity.

To test the "lemons" hypothesis, we compare market outcomes on the customer market and on the "anonymous market". Note that our anonymous market does not correspond to an "auction market" as characterized by Okun. On auction markets homogenous goods are 
traded, and trading is organized as in exchanges for stocks or raw materials. Such markets are most closely approximated by experimental double auction markets. In contrast, we compare two posted-offer markets in which sellers post prices and in which goods are nonhomogenous. We do not compare our customer market to a double auction market because to isolate the role of long-term relations we need to compare two settings which are otherwise identical (ceteris paribus variation).

The second hypothesis we test is the "invisible handshake" hypothesis $\mathrm{H} 2$. We analyze whether price increases on the customer market tend to undermine trust and disrupt the customer relation. Because we investigate markets with quality uncertainty, both increasing one's price and providing low quality may disrupt the customer relation. For example, Okun (p. 154) suggested that "once the firm draws a clientele with attractive implicit contracts, any deviation unfavorable to customers is seen as a violation of these contracts." Hence, our design also serves to investigate the relative importance of price and quality changes.

The third proposition we test is the "cost justification" hypothesis H3. We investigate whether customers are more willing to tolerate price increases if these are justified by cost increases. To this end, we compare price adjustment on the customer market when buyers are informed about the cost shock with a situation where buyers are not informed about the shock. Hence, we do not compare a cost and a demand shock to investigate the validity of the "cost justification" hypothesis. Okun suggested that prices are more flexible after a cost shock than after an increase in demand because price increases are perceived as more fair by customers in the former case. However, comparing cost and demand shocks involves a loss of experimental control because cost and demand shocks may differ in several dimensions. Instead, our

1 Note that the mechanism that leads to the "lemons outcome" of low quality at low prices in our paper as well as in the studies cited in this section is of the moral hazard type, while the mechanism described by Akerlof (1970) is of the adverse selection type. 
approach of implementing a controlled variation of information conditions tests hypothesis H3 more directly.

Supportive evidence for $\mathrm{H} 3$ is provided by Blinder et al. (p. 157). The authors ask managers: "Does the understanding that prices should remain fixed hold when your costs increase, or do customers see price increases as justified when costs increase?" The responses ( $n=111)$ were as follows: "When costs increase, our customers normally a) still want us to hold our prices $(15.3 \%)$, b) attitudes are mixed (13.5\%), tolerate price increases $(71.2 \%)$." Note that these findings reflect managers' beliefs about customers' price tolerance. However, we cannot infer from these responses how managers' beliefs translate into actual pricing decisions or firm profits. For example, are managers willing to antagonize 15 or maybe 30 percent of their customers to increase profits on the remaining customers? While questionnaire studies are particularly useful to obtain information about decision-makers' beliefs and attitudes, they are inapt to study market interaction, and ultimately, price rigidity. In contrast, our experiment analyzes market interaction under controlled conditions, but motives of market participants must be inferred from observed behavior.

\section{Experimental Design}

Section 3.1 provides a general description of the design and section 3.2 explains the procedures and parameters in detail. Section 3.3 presents the predictions.

\subsection{General description of the experimental design}

In our experiment, two markets operate simultaneously: a customer market (CM) and an anonymous market (AM). In both markets, an experience good is traded. That is, buyers only learn the quality of the good after the purchase. The essential difference between the two markets consists in the possibility to become a repeat customer. In the $\mathrm{CM}$, buyers and sellers 
can trade with the same partner repeatedly. Buyers receive an offer from a particular seller, and decide whether to uphold their relation with this specific seller. In contrast, the AM is anonymous. In the AM, buyers face offers from a number of unknown sellers, and due to the anonymity of the market, they cannot establish a customer relation with a specific seller.

In the $\mathrm{CM}$ one buyer and one seller are matched at the beginning of a trading phase. In each period the seller posts a price to his buyer, and chooses the quality he provides in case the buyer accepts. If the buyer accepts his seller's price offer, he learns the quality of the good, and is re-matched with the same seller in the next period. Thus, the customer relation is upheld as long as the buyer continues to accept his seller's offers. However, if the buyer rejects an offer from his seller, the customer relation is terminated. As a consequence, both the buyer and the seller participate in the AM from this period on. According to this procedure, the customer relation starts with an exogenous match, but is endogenously upheld by customers. The reason why we start the relation with an exogenous match is that the focus of our study is on trust within the relation, not on consumer search.

In the AM all sellers simultaneously post prices to all buyers. Buyers see a list of anonymous price offers and can choose from these offers in random order. If a buyer accepts an offer, neither the seller nor the buyer can identify the trading partner. Hence, trading in the AM is completely anonymous. All buyers and sellers who are in the AM in a particular period remain there for the rest of the trading phase. A consequence of this procedure is that market participants can only switch from the CM to the AM, but not from the AM to the CM. This procedure implements a "grim trigger" strategy by customers. This enforces an "unforgiving" behavior that is empirically plausible (Engle-Warnick and Slonim (2003) show that this strategy is chosen by about 80 percent of the first movers in infinitely repeated trust games). This grim trigger strategy provides sellers in our experiment with strong incentives not to antagonize customers since customers cannot return to the seller at a later point. 
To investigate the effect of information about the cost shock, we implement two treatment conditions (see table 1). In the treatment labeled PRIVATE, only the sellers are informed about the cost shock, while in the treatment called PUBLIC both sellers and buyers are informed about the cost shock.

Table 1: Overview over experimental conditions

\begin{tabular}{|c|c|c|}
\cline { 2 - 3 } \multicolumn{1}{c|}{} & \multicolumn{2}{c|}{ Information about cost shock is } \\
\cline { 2 - 3 } \multicolumn{1}{c|}{} & PRIVATE & PUBLIC \\
\hline Customer market $(\mathrm{CM})$ & CMPrivate & CMPublic \\
\hline Anonymous market (AM) & AMPrivate & AMPublic \\
\hline
\end{tabular}

\subsection{Procedures, parameters and information conditions}

Each experimental session has 5 trading phases with 10 periods each. In all sessions, 8 sellers and 4 buyers participate. In each period a seller can at most sell one unit of the good and a buyer can buy at most one unit. At the beginning of each trading phase 3 sellers and 3 buyers are randomly matched as trading pairs starting on the CM. All other participants start on the AM. As a consequence, there are at least five sellers and one buyer on the AM plus all trading pairs who at some point have terminated the customer relation in the CM. This constellation implies that there is always an excess supply on the AM of 4 units of the good.

Participants can earn points by trading. These points are converted into money at the end of the experiment at a commonly known exchange rate. Participants' payoffs are Price Seller Costs for a seller and Buyer Value - Price for a buyer if a trade is concluded, and zero otherwise. 
Table 2: Buyer values and seller costs

\begin{tabular}{|c|c|c|c|}
\hline & buyer values & seller costs & surplus \\
\hline High quality & 200 & $80(t=3: 120)$ & $120(80)$ \\
\hline Low quality & 100 & $40(t=3: 60)$ & $60(40)$ \\
\hline
\end{tabular}

Table 2 shows the parameters of buyer values and seller costs. High quality is twice as valuable for buyers, but providing high quality is also twice as costly to the sellers as providing low quality. Therefore, the total surplus of a high-quality trade is twice the surplus of a low-quality trade. Since quality differences directly translate into efficiency differences, we will concentrate on reporting quality differences below. In period $t=3$ of each trading phase a temporary cost shock of 50 percent occurs. Hence, costs increase from period 2 to 3 from 80 to 120 for a high-quality good, and from 40 to 60 for a low-quality good. Note that costs fall back to the previous level from period 4 on.

The information conditions are as follows: In both treatments the payoff calculation, the number of trading phases and periods, as well as the buyer values are common information. The subjects do not know exactly how many sellers and buyers there are on the AM and the $\mathrm{CM}$, but they are informed that there are always more sellers than buyers in the AM. The exact seller costs given in table 2 are only known to the sellers, but the buyers know that seller costs are lower for delivering low quality than for high quality, and that the costs are the same for all sellers.

The two treatments exclusively differ with respect to the information about the cost shock. In both conditions, sellers are informed about the cost shock at the beginning of period 3. Buyers are informed about the cost shock in PUBLIC but are not informed about the shock in PRIVATE, and this is known to sellers. In particular, the information sellers obtain in 
PRIVATE has three aspects. Sellers know a) that costs increase by 50 percent, b) that this cost shock is temporary (they know that costs will fall back to the previous level in period 4), and c) that buyers are not informed about a) and b). In PUBLIC, a) and b) hold for both buyers and sellers, and sellers know that buyers are informed about a) and b). Note that our observations from period 3 are responses to the cost shock because participants are informed about the cost shock at the beginning of period 3 .

At the beginning of each session the participants are randomly assigned to one of the booths in the computerized laboratory (we use the software z-tree, Fischbacher 1999). Written instructions are handed out which explain the experimental procedures in detail. ${ }^{2}$ All subjects read instructions for both roles. There are no control questions, but subjects can ask questions before the experiment starts. Roles are randomly assigned in the first period and kept throughout the entire session. The written instructions contain no information on the sellers' cost parameters, which are only displayed on sellers' computer screens from period $1 \mathrm{on}$. The information on the cost shock is shown on a separate screen that appears at the beginning of period 3. In PRIVATE, the screen explicitly states that the information about the shock is shown to sellers only and that buyers do not have any information about the cost shock. In PUBLIC, the screen is shown to both buyers and sellers, and the information about the cost shock is announced aloud by the experimenter.

At the end of each period, subjects in both treatment conditions only get information about the outcomes (i.e., price, quality, and own profit) of their own transaction. That is, neither participants in the CM nor in the AM know about market outcomes (like average quality, transaction prices etc.) in the AM. Hence, both markets are opaque in the sense that no information about overall market outcomes is provided to market participants.

\footnotetext{
2 Instructions are available from the authors upon request.
} 


\subsection{Predictions}

In the AM, the theory of competitive markets predicts the "lemons outcome", according to which low quality is provided at a low price. In particular, because of the anonymity of market interaction in the AM, a rational and self-interested seller always provides low quality. Because of the excess supply (of 4 units in each period) in the AM, prices should be driven down to the cost of providing low quality, i.e., to 40 units (see table 2). However, we expect convergence to be slow and imperfect in the AM for three reasons. First, the AM is opaque in the sense that market participants only get information about their own transaction, but not about market outcomes. This lack of market feedback information is expected to lead to slow convergence (see Cason and Friedman for an extended discussion). Second, sellers in our experiment know buyer values, and fairness considerations may prevent prices from falling to costs. In particular, sellers may be reluctant to undercut each other knowing that the entire surplus goes to the buyers if prices equal costs. Third, buyers may trust sellers despite the anonymity of market interaction. It is known from many experimental studies on trust games that people have a tendency to trust others even in perfectly anonymous one-shot interactions (e.g., Berg, Dickhaut and McCabe1995).

Two features of the CM contribute to the persistence of long-term customer relations. First, markets are opaque. Participants in the CM only get feedback about their own market transaction, but do not know qualities and prices provided on the AM. Therefore, buyers have insufficient information to rationally determine whether to remain with their seller or whether to terminate the customer relation to "experiment", i.e., to uncover prices and qualities on the AM. However, a particular rule of our experiment may induce customers to remain with their seller. The rule is that the termination of a relation cannot be revoked. This rule makes "experimentation" potentially more expensive for buyers because they cannot return to the $\mathrm{CM}$ upon finding out that they earn less on the AM than on the CM. However, buyers know 
that the experiment has 5 phases in which participants can gather experience with both markets. Hence, we would expect customer relations to be terminated at a higher rate in early phases and in late periods.

The second feature contributing to the persistence of long-term relations is that buyers may trust sellers to provide high quality. Suppose a buyer trusts a seller to provide high quality, and, upon receiving high quality at a "fair price", continues to trust the seller. Suppose further that the buyer terminates the relation upon receiving bad quality or upon experiencing a price increase. Then, the seller is tempted in each period to reap a one-time gain by providing low quality, but has to trade off this one-time gain against the cost of losing his customer. While this cost is not known exactly to the seller because the market is opaque, it may be profitable for the seller to provide high quality if the relation can be maintained for sufficiently many periods with sufficient probability (see Brown et al. for a more detailed account). A similar reasoning applies to price choices after the cost shock. Accordingly, a seller may find it profitable to refrain from increasing his price after the shock to avert antagonizing and losing his customer.

The remaining potential length of the customer relation may be an important determinant of termination for two reasons. First, antagonizing the customer on the CM is more costly for the seller in early periods because the risk of not being able to trade on the $\mathrm{AM}$ is higher in early periods. Second, if the customer terminates the relation in an early period, more periods of profitable interaction on the CM are foregone (see James 2002 for a more detailed analysis). These two factors lead us to expect that customer relations tend to be terminated at a higher rate in late periods. However, since termination incentives are opposite for buyers and sellers, we have no clear prediction for the rate with which relations end. 


\section{Results}

We conducted 12 runs in each treatment at the University of Erfurt. In total, 288 undergraduate students from various disciplines participated in our experiment. Subjects earned $€ 15.3$ (US\$15, approx.) on average within about 120 minutes.

Table 3 summarizes important differences between the CM and the AM. The table shows the quality and prices averaged over all subjects, phases and periods. As can be seen in the table, high quality is provided about three times as often in the CM as in the AM. In particular, high quality is provided in 59 percent of the transactions in the $\mathrm{CM}$, but only in 20 percent in the AM. We henceforth code high quality as 1 , and low quality as 0 . This allows us to speak of the percentage of high quality provided as "average quality". Higher quality in the $\mathrm{CM}$ comes at a higher price. In fact, the average price is 45 percent higher in the $\mathrm{CM}(115.1)$ than in the AM (79.9).

Table 3: Overview (averages, all periods, all phases, both treatments)

\begin{tabular}{|c|c|c|}
\hline & $\begin{array}{c}\text { Customer Market } \\
(\mathrm{CM})\end{array}$ & $\begin{array}{c}\text { Anonymous Market } \\
(\mathrm{AM})\end{array}$ \\
\hline Traded Quality & 0.59 & 0.20 \\
\hline Transaction Price & 115.1 & 79.9 \\
\hline Buyer Earnings & 43.9 & 39.7 \\
\hline Seller Profits & 47.8 & 12.2 \\
\hline
\end{tabular}

Since trading high quality fully translates into higher gains from trade (see table 2), the customer market yields considerable efficiency gains. In addition, both buyers and sellers earn more on the CM. In particular, average buyer earnings are 43.9 on the CM and 39.7 on the 
AM, and average seller profits are 47.8 on the $\mathrm{CM}$, but only 12.2 on the AM. Hence, upholding the customer relation is mutually profitable on average.

Statistical testing for differences between the $\mathrm{CM}$ and the $\mathrm{AM}$ is problematic. The reason is that observations from the two markets are not strictly independent. For example, prices in the AM might be affected by the experience of subjects who were exogenously allocated to the CM but failed to uphold the relation. As a consequence, selection problems prevail. Thus, we test for differences between the CM and the AM by considering the strictly independent observations of the first period in the first phase. We test transaction prices of those who were exogenously allocated to the CM (average 103.8) against those who were exogenously allocated to the AM (average 85.7). A Mann-Whitney test reveals that transaction prices are indeed higher in the $\mathrm{CM}(p=0.010$, one-tailed test). Comparing quality choices analogously across the CM (0.44) and the AM (0.22) yields a weakly significant difference $\left(p<0.100\right.$, Chi-square test, $\left.\chi^{2}=3.24, d f=1\right)$. Seller profits are significantly higher ( $p=0.000$, Mann-Whitney test) in the first period in the CM (45.9) than in the AM (9.2). Buyer earnings are also higher in the CM (40.9) than in the AM (32.3) in period $1(p=0.000$, Mann-Whitney test).

We conclude that while the AM did not fully converge to the lemons outcome, the CM produced much better market outcomes. Average quality on the $\mathrm{CM}$ is much higher, and trading on the $\mathrm{CM}$ is mutually profitable for buyers and sellers. Hence, long-term relations in the $\mathrm{CM}$ at least partially resolved the lemons problem, as suggested by hypothesis $\mathrm{H} 1$.

\section{A) Pricing in customer markets}

We now discuss how trust in customer markets affects prices, and, in particular, how price responses differ across markets and treatments. Subsection B) considers quality, C) profits, and D) analyzes the determinants of customer relations. 
Figure 1: Average transaction prices with public information (PUBLIC)

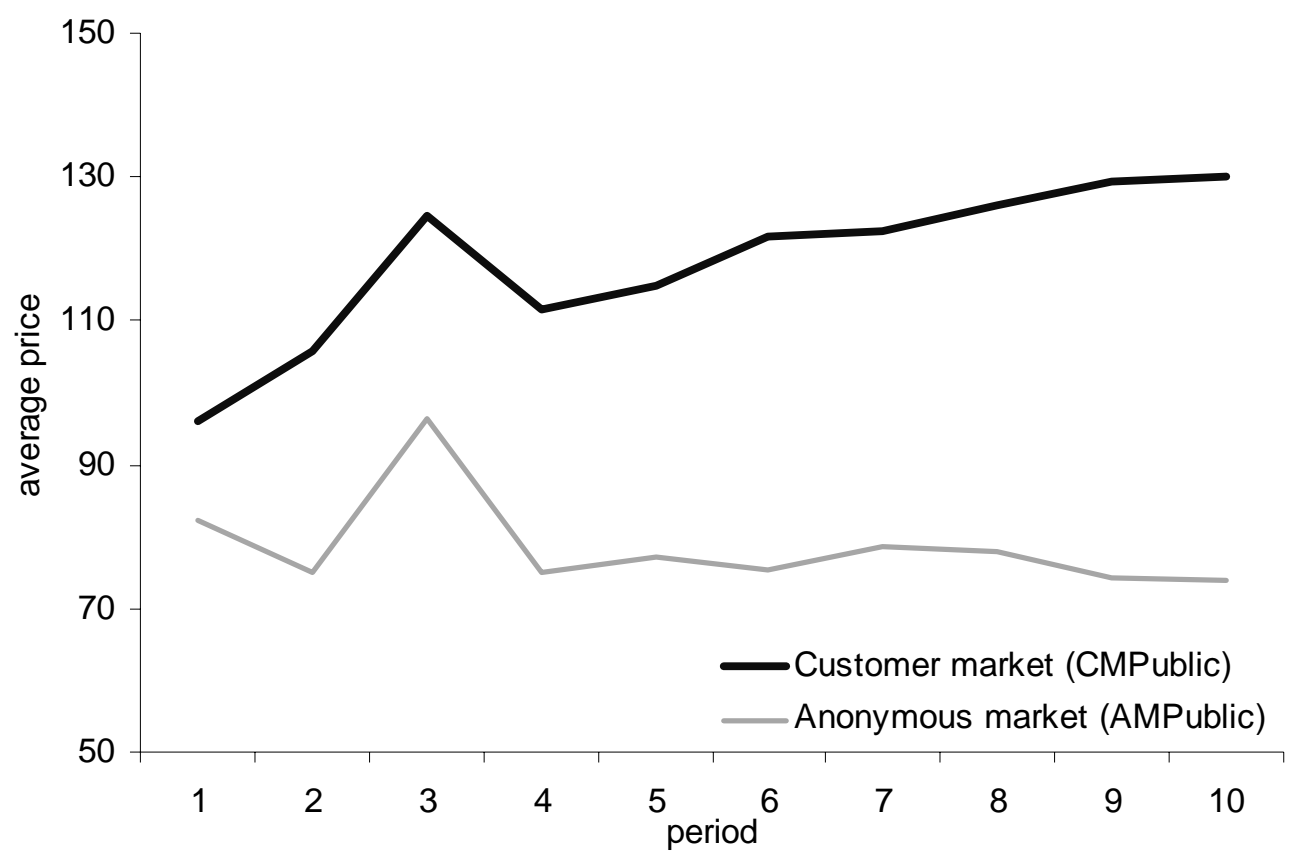

Figure 1 shows average transaction prices per period in the two markets with public information (PUBLIC). To facilitate the exposition, we aggregate prices over all 5 phases (see appendix $\mathrm{C}$ for average prices in each phase). Several facts are evident from inspection of figure 1. First, prices are higher in CMPublic than in AMPublic. Second, prices do respond to the cost shock in both AMPublic and in CMPublic. Third, average prices are relatively stable in AMPublic, but tend to increase in CMPublic. Increasing prices in CMPublic result from a selection bias. The buyers with the lowest "tolerance" for high prices (i.e., those with the lowest degree of trust that the seller will provide high quality) tend to drop out of the CM in early periods. In addition, higher quality is strongly associated with higher prices, and providing low quality tends to disrupt the customer relation (see section D). As a consequence, customer relations exhibiting low prices and low quality tend to be disrupted first.

Figure 2 shows average transaction prices in the two markets when information is private (PRIVATE). As with public information, average prices are higher in CMPrivate than in AMPrivate, and prices have a positive trend in CMPrivate which is absent in AMPrivate. 
We again observe a pronounced reaction to the cost shock in period 3 in AMPrivate, but average prices do not seem to respond to the cost shock in CMPrivate. However, the price responses are difficult to assess from mere inspection of the figures because price responses are obscured by the upward trend in $\mathrm{CM}$ which results from the selection bias.

Figure 2: Average transaction prices with private information (PRIVATE)

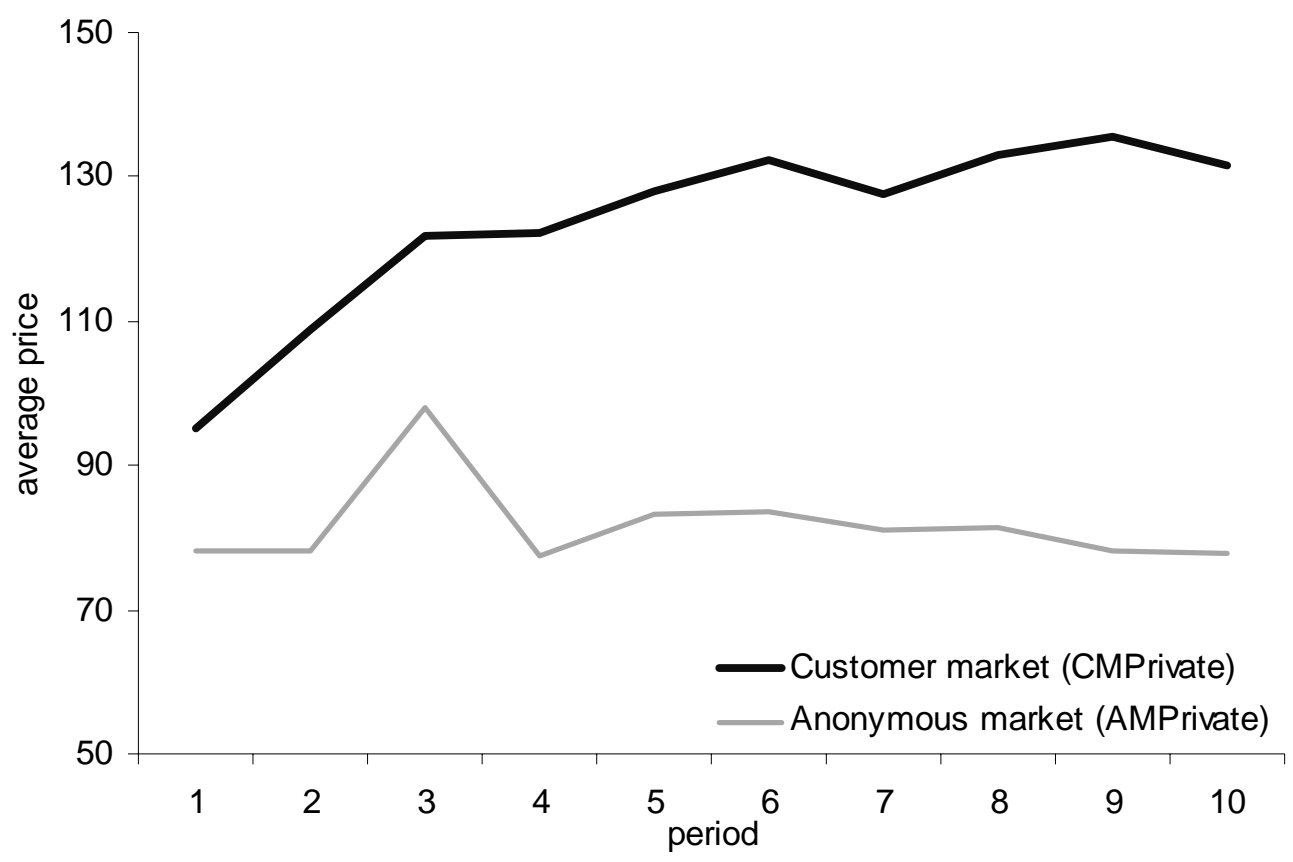

The simplest way to correct for this selection bias is to consider price changes. We calculate how individual sellers' transaction prices responded to the cost shock (i.e., changed from period 2 to 3 ). Note that we correct for the bias by only considering transaction prices of those sellers in period 2 who also transacted in period 3 . The average price response in the $\mathrm{CM}$ (for both information conditions and all phases) is 11.2, while it is 19.8 in the AM.

To evaluate the "invisible handshake" hypothesis $\mathrm{H} 2$, we examine whether prices are more rigid in the $\mathrm{CM}$ than in the $\mathrm{AM}$. We use the relative under-reaction of prices in the $\mathrm{CM}$ as a measure of price rigidity. For example, $[(\Delta \mathrm{CM}-\Delta \mathrm{AM}) / \Delta \mathrm{AM}]$ measures price rigidity for both information conditions jointly, where $\Delta$ is the average change in transaction prices 
from period 2 to 3 . According to this measure, prices were 43.4 percent $[=(11.2-19.8) /$

19.8] more rigid in the $\mathrm{CM}$ than in the AM which provides support for hypothesis $\mathrm{H} 2$.

Table 4: Price adjustment in response to cost shock

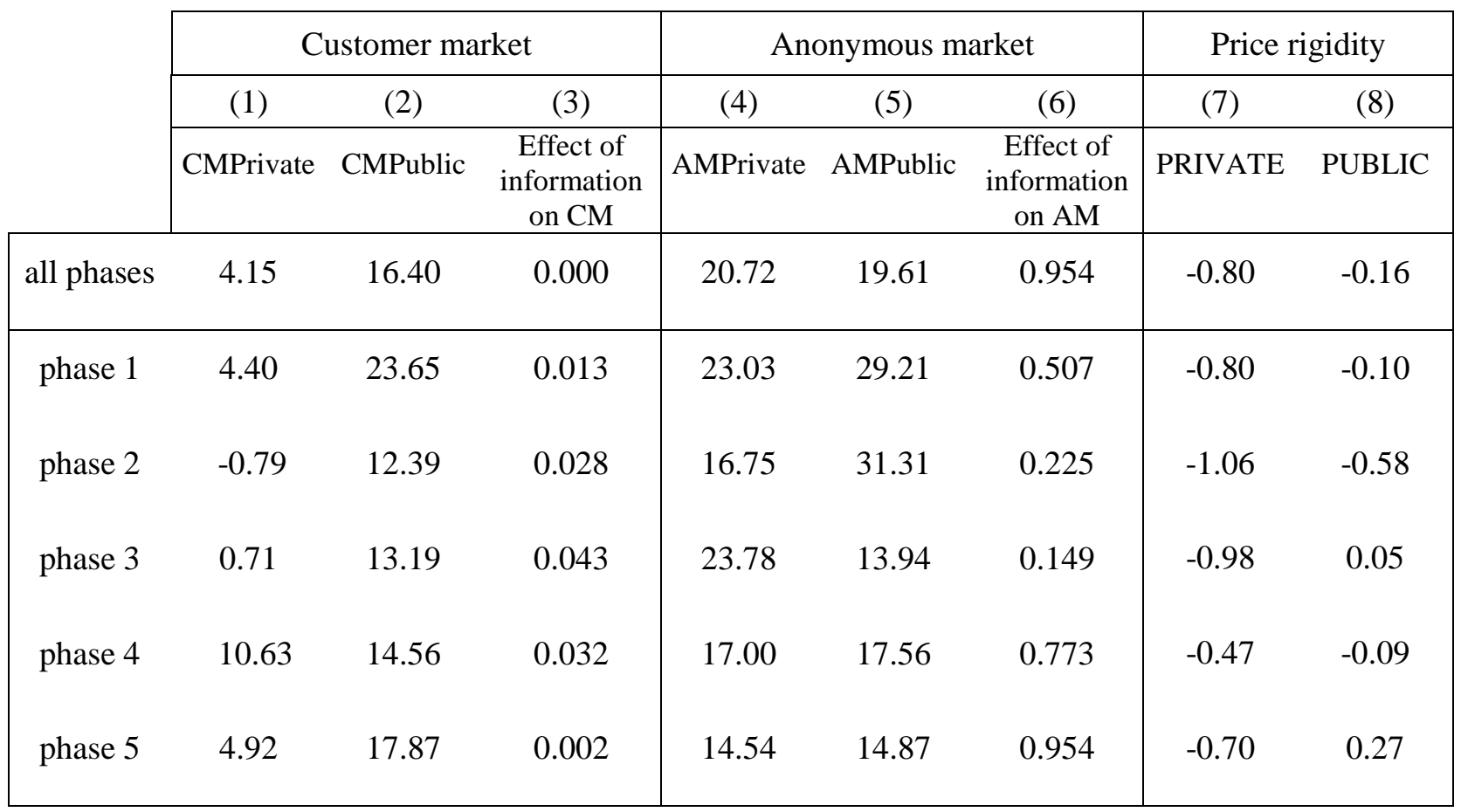

Notes: Columns (1), (2), (4) and (5) show the average change of transaction prices from period 2 to period 3 (= $\Delta$ ). Columns (3) and (6) test for the effect of information on price adjustment. They show $p$-values of MannWhitney tests (one-tailed for CM, two-tailed for AM). Columns (7) and (8) show price rigidity measured by the average underreaction of price changes in the $\mathrm{CM}$ according to [( $\Delta$ CMPrivate - $\Delta$ AMPrivate $) /$ $\Delta$ AMPrivate $]$ and $[(\triangle \mathrm{CMPublic}-\triangle \mathrm{AMPublic}) / \Delta$ AMPublic $]$, respectively. All $\mathrm{CM}$ values are changes of transaction prices for a given customer relation.

To evaluate the "cost justification" hypothesis $\mathrm{H} 3$, we compare price responses in the customer markets across information conditions. At the individual level, we find that 79.6 percent of sellers increase their prices in CMPublic, while only 40.3 percent of sellers do in CMPrivate. When aggregating over all 5 phases, we find that the average price response to the cost shock is almost 4 times more vigorous with public information (16.4, see column 2 of table 4) than with private information (4.2) in the CM. Mann-Whitney tests show that prices 
respond significantly more in CMPublic than in CMPrivate. This is true when aggregating over all 5 phases $(p=0.000)$, and also holds at the 5 percent level for each individual phase (see column 3).

To evaluate the effect of information about the cost shock on price rigidity, we have to compare the relative underadjustment of prices in the CM across treatments. Table 4 shows that the average price response over all 5 phases is vigorous in AMPrivate (20.7, see first line of column 4) but weak in CMPrivate (4.2, see column 1). The same holds for individual phases. For example, the average response was in excess of 14.5 in each phase of AMPrivate, but was close to 0 in two phases in CMPrivate. In contrast, price responses are much more similar in the two markets with public information (19.6 vs. 16.4). As a consequence, overall prices are 80 percent more rigid in the $\mathrm{CM}$ than in the $\mathrm{AM}$ with private information, but only 16 percent more rigid with public information (see columns 7 and 8 of table 4 ).

If we analyze the responses of posted prices (rather than accepted prices as above) across information conditions in the customer market, we find that price offers on average increase by 7.5 in CMPrivate, and by 17.1 in CMPublic. This difference across information conditions is highly significant ( $p=0.000$, Mann-Whitney), and suggests that sellers anticipated that they tend to be turned down by customers if they increase prices too much without justification (i.e., in CMPrivate).

In all, we conclude that customer markets cause pronounced price rigidity if price increases cannot be justified by cost increases, but that price rigidity is much less pronounced if the price increase is justified by a cost increase, as suggested by hypothesis H3.

\section{B) Quality}

Figure 3 shows the percentage of transactions in which high quality is provided (“average quality") for both markets and information conditions. Average quality is higher in 
the $\mathrm{CM}$ than in the AM from period 1 on. While quality is relatively stable at low values in the AM, quality further increases in the $\mathrm{CM}$ to its peak in period 9, and then sharply falls in period 10. The increase in quality until period 9 reflects that higher quality tends to be associated with higher prices in the CM. Again, this increasing trend can be explained by a selection bias. Since providing low quality tends to disrupt the customer relation, customer relations with high quality tend to be upheld at a higher rate (see section D for details).

Figure 3: Average quality

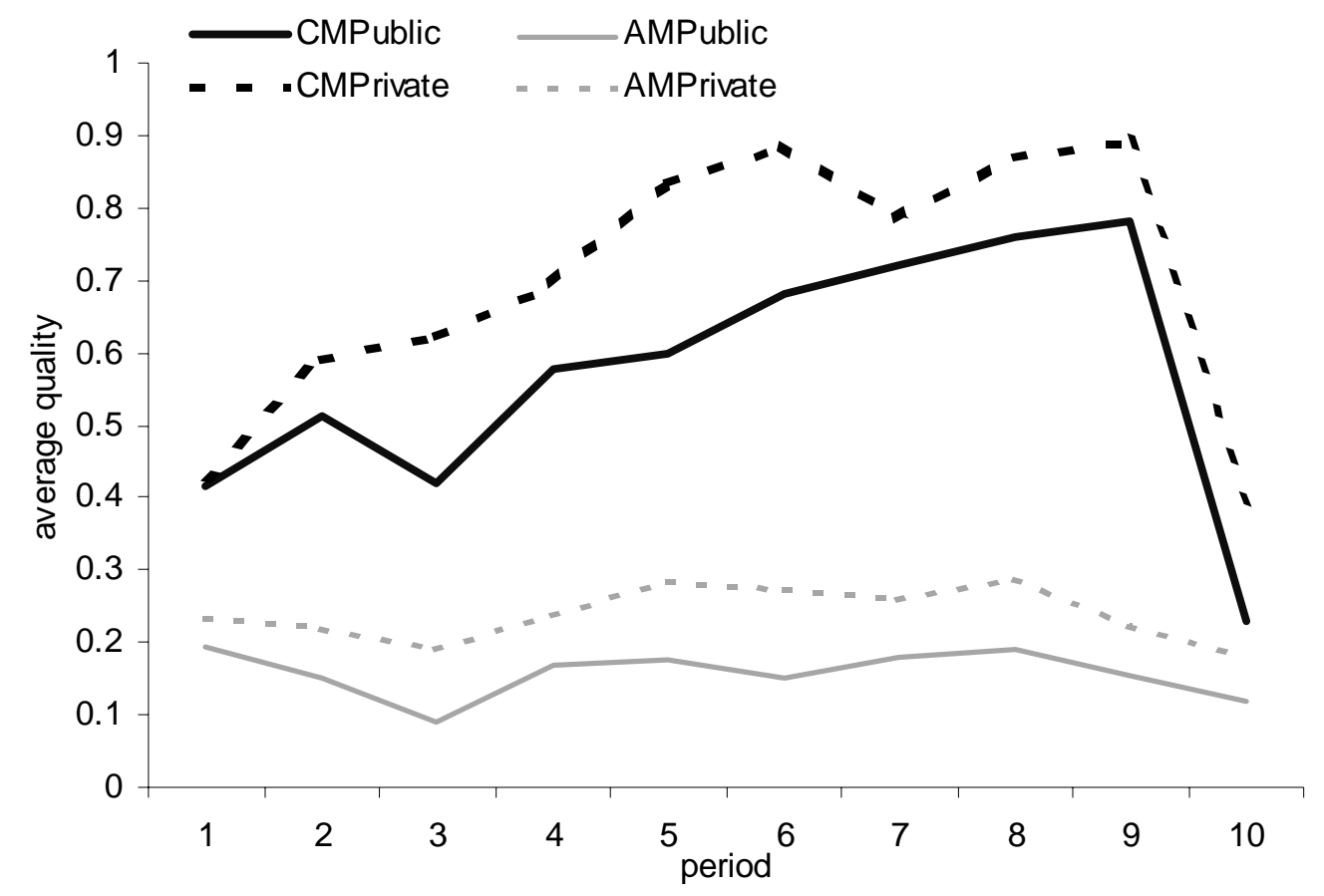

The sharp drop in period 10 is an "endgame" effect that is frequently observed in finite trust (and public goods) games (e.g., Selten and Stoecker 1986). This sharp drop suggests that sellers provide high quality in the CM for strategic reasons. Sellers seem to have understood that providing low quality tends to disrupt the customer relation, and that upholding the relation is profitable (see table 3). However, providing high quality ceases to be profitable for sellers in the last period since it cannot induce customer loyalty, i.e., induce a buyer to uphold the relation by definition. It is remarkable that finite long-term relations are apt to induce systematically higher quality in the CM than in the AM up to period 9. Remember that all 
participants knew that the customer relation can at most last for 10 periods. Accordingly, depending on players' rationality and experience, one would expect quality to fall at some point before the end of the game (see Ch. 5 in Camerer 2003). However, the results of EngleWarnick and Slonim suggest that players behave relatively similar in a simple finite trust game (5 period) and an equivalent infinite trust game. The authors find that a lot of experience is needed (more than 20 repetitions) to yield clear behavioral differences between the finite and the infinite game. We only repeat the game 5 times (phases), and find no significant differences in buyer trust (breakup) or seller trustworthiness (quality) over phases.

Figure 3 seems to suggest that the cost shock depresses quality more with public than with private information. However, the decline in quality is not significantly different in the AM across information conditions (Mann-Whitney test, $p=0.323$ ). If we control for the selection bias in the $\mathrm{CM}$ analogously as for prices (i.e., by considering how quality within a customer relation changes from period 2 to 3), we find the following. Average quality falls by 12.5 percentage points (from $75 \%$ to $62.5 \%$ ) in CMPrivate, and by 17.4 percentage points (from $59.1 \%$ to $41.8 \%$ ) in CMPublic. However, these changes are not significantly different ( $p>0.3$, Chi-square test, $\chi^{2}=1.84, d f=2$ ). We conclude that the information about the cost shock had no significant effect on quality.

\section{C) Profits and Earnings}

Upholding the customer relation is profitable for both buyers and sellers on average (see table 3). However, the gains from trusting on the CM are unequally distributed. Sellers benefit much more from upholding the relation than buyers. In particular, sellers earn almost four times as much in the CM than in the AM (47.8 vs. 12.2), but buyers on average only earn 10.2 percent more in CM than in AM (43.9 vs. 39.8). This implies that buyers can sanction sellers by terminating the relation, and that sellers have a strong incentive not to antagonize 
customers by increasing prices or by providing low quality. The average "sanction" of terminating the relation for a seller is 35.2 per period $(=47.8-12.2)$, and results from two sources. First, trading on the AM is less profitable for sellers because prices are lower on the AM than on the CM. Second, and more importantly, there is a high risk of not being able to trade on the AM which means that seller earnings are zero.

An interesting question is who bears the burden of the cost shock in the customer market. Of course, the cost shock depresses overall earnings since the gains from trade fall by a third, ceteris paribus (see table 2). Since the relation is profitable for sellers, they should be willing to bear the burden of the cost shock if doing so contributes to uphold the relation. According to hypothesis $\mathrm{H} 3$, the extent to which it does depends on the information available to customers. Hence, we would expect that sellers bear more of the burden when information about the shock is private than when it is public. This is indeed the case. With private information, the sellers bear the brunt of the cost increase because they are reluctant to increase prices, and reduce quality only a little. In particular, seller losses in period 3 (as a percentage of period 2 profits) are more than twice as large as buyer losses (46.3 vs. 18.9 percent) on the $\mathrm{CM}$ when information is private. In contrast, with public information, buyers on the CM suffer losses that are about five times as large as seller losses. In particular, with public information buyers lose 62.3 percent of their earnings, while sellers only lose 12.6 percent of their profits (again relative to period 2). Hence, sellers are able to shift the burden of the cost shock to customers with public information but not with private information.

Interestingly, there are no pronounced long-term effects of the cost shock on seller profits or customer earnings in the CM. If we test seller profits across treatments by period (Mann-Whitney tests), we only find a significant difference in period $3(p=0.002)$, all other periods are insignificant $(p>0.487)$. Buyer earnings are only different in periods $3(p=$ $0.010)$ and $6(p=0.011)$ at the 5 percent level. 


\section{D) Customer relations}

In total, 360 trading pairs start on the $\mathrm{CM}(=12$ runs $\times 3$ pairs $\times 2$ treatments $\times 5$ phases). These pairs can uphold their relation for at most 10 periods. The average breakup rate is similar in both treatments (16.4\% in CMPrivate, $17.2 \%$ in CMPublic). The difference between the two treatments is at a maximum in the shock period (34.5\% in CMPrivate, $20.3 \%$ in CMPublic). In the last period, the breakup rate is remarkably high (24.3\% in CMPrivate, $36.6 \%$ in CMPublic). As a consequence, still 47.2 percent of all possible customer relations are upheld in period 3, while this percentage drops to 15.0 in period 10.

To analyze the determinants of customer relations, we run a maximum likelihood probit regression (see table 5). A probit regression has the advantage that the estimates for dummy variables can be interpreted as the change in probability of a breakup. In particular, $\mathrm{D} F / \mathrm{d} x$ is the marginal effect for a discrete change of the dummy variable from 0 to 1.

The insignificant estimate for (1) Treatment shows that the probability to terminate the relation is not different with public or with private information, which is what we expect in all non-shock periods. Phase (2) is insignificant, and Period (3) is weakly negative. This suggest that relations tend to break-off early in a phase, but the tendency to uphold relations is not different across phases. Both of these findings are surprising. Given our discussion of search in opaque markets in section 3.3, we would have expected customer relations to be more prevalent in late phases, when participants have gained experience with the market institutions. The (weakly significant) negative estimate for (3) is surprising since firms should be more hesitant to provide bad quality in early periods than in late periods (where the cost of terminating the relation is lower). However, this seems only to hold for the very last period. The estimate for Last period (4) indicates that the probability that a relation is terminated is 34.77 points higher in the last period than in other periods. This suggests that some customers anti- 
cipated that sellers are not going to be trustworthy and will deliver low quality in period 10 (as most of them do, see figure 3). Hence, many customers seem to understand that sellers can be more reliably trusted if they have an incentive to be trustworthy. But when this incentive is altogether absent in the last period, a considerable portion of customers ceases to trust.

Table 5: Probit regression

\begin{tabular}{|c|c|c|c|}
\hline & $\begin{array}{l}\text { dependent Variable: probability of breakup of } \\
\text { customer relation }\end{array}$ & $\mathrm{d} F / \mathrm{d} x$ & $P>|z|$ \\
\hline (1) & Treatment (dummy, 1 = PUBLIC) & .0079 & 0.731 \\
\hline (2) & Phase & .0093 & 0.218 \\
\hline (3) & Period & $-.0121 *$ & 0.024 \\
\hline (4) & Last period (dummy) & $.3477 * * *$ & 0.000 \\
\hline$(5)$ & Shockperiod (dummy) & $.1556 * * *$ & 0.000 \\
\hline (6) & Shockperiod $*$ public info (dummy) & $-.1177 * *$ & 0.001 \\
\hline (7) & This period's posted price & $.0030 * * *$ & 0.000 \\
\hline (8) & Price increase from last period (dummy) & $.0702 *$ & 0.020 \\
\hline (9) & Extent of price change from last period & -.0000 & 0.998 \\
\hline$(10)$ & Large (> 30 units) price increase (dummy) & $-.1104 *$ & 0.010 \\
\hline (11) & Large (> 30 units) price cut (dummy) & .0624 & 0.403 \\
\hline (12) & Last period bad quality (dummy) & $.3986 * * *$ & 0.000 \\
\hline
\end{tabular}

Notes: $n=1346$, Prob $>\mathrm{Chi}^{2}=0.0000$, Log likelihood $=-540.32$, Pseudo $R^{2}=0.1675$; $* * *=$ significant at the 0.1 percent level, $* *=1$ percent, $*=5$ percent.

Estimates (5) and (6) capture the effect of the shock period in the two treatments. The estimate for Shockperiod (5) indicates that the probability of separation is 15.56 points higher 
in period 3, and (6) suggests that the probability of breakup is 11.77 points lower with public information. Even though prices increase much less in CMPrivate than in CMPublic in response to the cost shock (see table 4), the breakup rate is higher in CMPrivate. This indicates that sellers only partly anticipated that customers are antagonized by unjustified price increases.

The estimates (7) to (11) jointly capture the effect of pricing on the termination of customer relations. (7) shows that higher levels of prices contribute to disruption, and (8) shows that if prices are increased, the probability of disruption is 7.0 points higher. Customers reacte to the extent of price increases in a rather surprising manner. Larger price increases (9) apparently do not additionally contribute to termination. Surprisingly, very large (by more than 30 units) price increases (10) reduce the probability of breakup. Apparently, very large price increases seem to be interpreted by customers as a signal that the seller is going provide high quality. In contrast, very large price cuts (11) do not reduce the probability of breakup. Finally, the quality provided by the seller in the previous period has the quantitatively strongest effect on termination. The highly significant estimate (12) shows that providing low quality increases the probability of termination of the customer relation by 39.9 points in the subsequent period.

\section{Concluding remarks}

This paper demonstrates how trust can shape market outcomes. In particular, we provide the first experimental investigation of how long-term customer relations cause price rigidity in markets for experience goods. While we believe that our study provides interesting insights, we also feel the need to further explore price rigidity in customer markets. Fortunately, our experimental design lends itself to investigate some additional aspects of 
price rigidity in customer markets. For example, the design can easily be adapted to analyze asymmetries in price rigidity. To do so, a negative cost shock could be implemented in period 3 and the price adjustment could be compared with the price response to the positive shock. It would also be interesting to further investigate the implications of strategic trust for price rigidity. We speculate that many sellers do not respond to the cost shock by increasing prices and are willing to bear the corresponding costs in period 3 because they hope to reap the gains from trading with loyal customers in the remaining 7 periods of the game. To test for the importance of this trade-off, one could implement a cost shock in, say, period 7 and compare this price response with the one in period 3. If strategic trust is important, price rigidity should be less pronounced after the shock in period 7 because the gains from trading with loyal customers can now only be reaped in fewer periods.

Four remarks concerning the interpretation of our results seem appropriate.

First, we show that finite long-term relations cause price rigidity in customer markets. In particular, it was known to all participants in our experiment that the customer relation can last for 10 periods at most. In contrast, standard theory must assume infinite horizons to demonstrate possible effects of customer relations with perfectly rational and self-interested agents (e.g., Klein and Leffler 1981). Fairness motives are likely to provide an explanation for this discrepancy (see appendix 1 of Brown et al. for a theoretical discussion).

Second, while the intuition that price increases may antagonize customers motivated our experiment, our findings also draw attention to the importance of quality reductions. In particular, our results show that providing low quality is even more disruptive to customer relations than price increases. Sellers anticipating this have an incentive to leave prices and quantities unchanged after temporary cost shocks. That customer relations may not only induce price rigidity but also "quality rigidity" is illustrated in the extreme example of the 
"Nickel Coke". Levy and Young (2002) argue that because of an implicit contract with its customers, Coca-Cola not only held the nominal price of a bottle constant over a period of 70 years (from 1886 to 1959), but also held quality constant over this period despite important cost and demand shocks. However, firms may be forced to choose between price and quality adjustments at some point. Whether price or quality rigidity is likely to be more pronounced may importantly depend on the relative "visibility" of price and quality changes. For example, the journal Consumer Reports $(1994,59(10)$, p. 618) reports that "the typical can of dog food once held 14 ounces. Now it holds 13.2 ounces. The can itself hasn't changed - and neither has the price." Rotemberg (2002) provides further examples of how almost imperceptible quality reductions can be used to mask price increases.

Third, our study demonstrated that long-term relations cause price rigidity in a setting in which reputations for providing high quality could only prevail within the relation. That is, seller reputations were relation-specific in our experiment, and reputations could not be transmitted to other potential buyers. However, if sellers can develop general reputations through markets (e.g., by advertising) or social networks (see Huck and Tyran 2003), incentives for upholding personal long-term relations can be much different than in the absence of these transmission channels.

Fourth, we find that long-term relations are profitable for sellers in our experiment. However, while long-term relations clearly have benefits, they may also have drawbacks in more complex environments. For example, Grayson and Ambler (1999) suggest that longterm customers may hold higher expectations on service quality than one-time customers. Since higher expectations increase the potential for dissatisfaction with a given service quality, firms may have to incur higher costs to avert termination of the customer relation. 


\section{References}

Akerlof, G.A., 1970. The Market for "Lemons": Quality Uncertainty and the Market Mechanism. Quarterly Journal of Economics 84 (3), 488-500.

Apel, M., Friberg, R. and Hallsten, K, 2001. Micro Foundations of Macroeconomic Price Adjustment: Survey Evidence from Swedish Firms. Working paper Sweriges Riksbank no. 128, Dec. 2001.

Arrow, K.J., 1973. Social Responsibility and Economic Efficiency. Public Policy 21 (3), 30317.

Berg, J., Dickhaut, J. and McCabe, K., 1995. Trust, Reciprocity, and Social History. Games and Economic Behavior 10 (1), 122-42.

Blinder, A.S., Canetti, E.D., Lebow, D.E., Rudd, J.B., 1998. Asking about Prices. A New Approach to Understanding Price Stickiness. New York, Russell Sage Foundation.

Brown, M., Falk, A. and Fehr, E., 2002. Contractual Incompleteness and the Nature of Market Interaction. Working paper Institute for Empirical Research in Economics no. 38, University of Zurich, February 2002.

Camerer, C., 2003. Behavioral Game Theory. Experiments in Strategic Interaction. Princeton, Princeton University Press.

Carlton, D.W., 1989. The Theory and Facts about how Markets Clear: Is Industrial Organization Valuable for Understanding Macroeconomics? In: R. Schmalensee and R.D. Willig (eds.), Handbook of Industrial Organization, Vol. I, 909-46.

Cason, T.N. and Friedman, D., 2002. A Laboratory Study of Customer Markets. Advances in Economic Analysis and Policy 2 (1), Article 1.

Engle-Warnick, J. and Slonim, R.L., 2003. The Evolution of Strategies in a Repeated Trust Game. Unpublished Working paper.

Fischbacher, U., 1999. ztree. Zürich Toolbox for Readymade Economic Experiments. University of Zürich, Working Paper No. 21.

Franciosi, R., Kujal, P., Michelitsch, R., Smith, V.L., Deng, G., 1995. Fairness: Effect on Temporary and Equilibrium Prices in Posted-Offer Markets. Economic Journal 105 (43), 938-50. 
Grayson, K. and Ambler, T., 1999. The Dark Side of Long-Term Relationships in Marketing Services. Journal of Marketing Research 36 (1), 132-41.

Huck, S. and Tyran, J.-R., 2003. Social Ties and Reciprocity in Markets for Experience Goods. Unpublished manuscript.

James, H.S., 2002. On the Reliability of Trusting. Rationality and Society 14 (2), 231-58.

Kachelmeier, S.J., Limberg, S.T. and Schadewald, M.S., 1991a. A Laboratory Market Examination of the Consumer Price Response to Information about Producers' Cost and Profits. Accounting Review 66 (4), 694-717.

Kachelmeier, S.J., Limberg, S.T. and Schadewald, M.S., 1991b. Fairness in Markets: A Laboratory Investigation. Journal of Economic Psychology 12 (3), 447-64.

Kahneman, D., Knetsch, J.L. and Thaler, R., 1986. Fairness as a Constraint on Profit Seeking: Entitlements in the Market. American Economic Review 76 (4), 728-41.

Klein, B. and Leffler, K.B., 1981. The Role of Market Forces in Assuring Contractual Performance. Journal of Political Economy 89 (4), 615-41.

Kollock, P., 1994, The Emergence of Exchange Structures: An Experimental Study of Uncertainty, Commitment, and Trust. American Journal of Sociology 100 (2), 313-45.

Levy, D and Young, A.T., 2002. "The Real Thing”: Nominal Price Rigidity of the Nickel Coke, 1886-1959. Working paper Emory University.

Okun, A.M., 1981. Prices and Quantities: A Macroeconomic Analysis. Washington, D.C.: the Brookings Institution.

Rotemberg, J., 2002. Customer Anger at Price Increases, Time Variation in the Frequency of Price Changes and Monetary Policy. NBER working paper 9320, November 2002.

Selten, R. and Stoecker, R., 1986. End Behavior in Sequences of Finite Prisoner's Dilemma Supergames. Journal of Economic Behavior and Organization 7 (1), 47-70.

Wynne, M.A., 1995, Sticky Prices: What is the Evidence? Economic Review, Federal Reserve Bank of Dallas, $1^{\text {st }}$ quarter, 1-12. 


\section{Appendix A: Instructions}

(Original instructions were in German. The instructions were the same in both treatments. In the private information treatment the information on the temporary cost shock was shown on sellers' screens only at the beginning of period 3. In the public information treatment the information about the cost shock was shown on all participants' screens.)

\section{General information on the experiment}

You are taking part in a market experiment. At the end of the experiment you will be paid according to the decisions you make. Please read these instructions carefully.

Earnings. During the experiment you earn points. The total income in points you earn during the experiment will be converted in Euros at the rate 1 point $=0.012 €$ and paid to you in cash.

Please note: During the experiment all participants decide independently and anonymously, i.e., no participant will ever learn the identity of the persons with whom he interacts.

Therefore it is imperative that all participants observe the following rule: During the experiment all communication is prohibited, i.e. you are not allowed to speak or express otherwise yourself. Should you have any questions please ask the experimenter.

\section{Overview of the experimental procedures}

In the experiment there are buyers and sellers. Whether you are a buyer or a seller will be randomly determined at the beginning of the experiment and displayed on your computer screen. You will keep your role throughout the whole experiment.

The experiment is divided into several trading periods.

In every trading period a seller can sell one unit of a good and a buyer can buy one unit of the good. The seller can produce the good either in high or in low quality. The quality determines the production costs the seller incurs and the value of the good to the buyer.

Sellers and buyers can earn points by concluding a trade. A seller earns points if he sells the good at a price which exceeds his costs of production, a buyer earns points if he buys a good whose value exceeds the purchase price.

In every period a seller's task is to determine the price at which he sells the good. Moreover, he determines whether he will deliver high or low quality. This determines the production costs he incurs and the value of the good to the buyer. At the time of purchase a buyer knows only the price but not the quality of the good and hence he does not know the value of the good.

\section{Calculation of your income in a period}

- Income of a buyer. For a buyer, a unit of a good has the following values: low quality: 100, high quality: 200. These values are the same for all buyers. The income of a buyer is calculated as follows: income $=$ value of the delivered good - price.

If a buyer decides not buy a good in a period, his income is 0 . If he buys at a price that exceeds the value of the good delivered, he makes a loss. Losses will be subtracted from your income. 
- Income of a seller. A seller has low production costs if he produces a low quality good and high production costs if he produces a high quality good. The exact production costs are only known to the sellers and will be displayed on the sellers' computer screen. The production costs are the same for all sellers.

If a seller does not sell his good in a particular period, his income is 0 in this period. If he sells his good, his income is calculated as follows:

income $=$ price - production costs subject to quality .

Every participant receives an additional 150 points at the beginning of the experiment.

\section{How to trade}

There are two markets: market I and market II. Trading rules differ across markets.

\section{Trading rules for market I}

On market I, a specific seller trades with a specific buyer, i.e. a seller and a buyer form a fixed matched trading pair as long as they are trading on market I. This means that you deal with the same person as long as you stay on market I.

A seller makes an offer by determining a price and the quality he will supply. This also determines his production costs and the value of the good for the buyer in case he accepts. On market I a seller sees the following input screen:

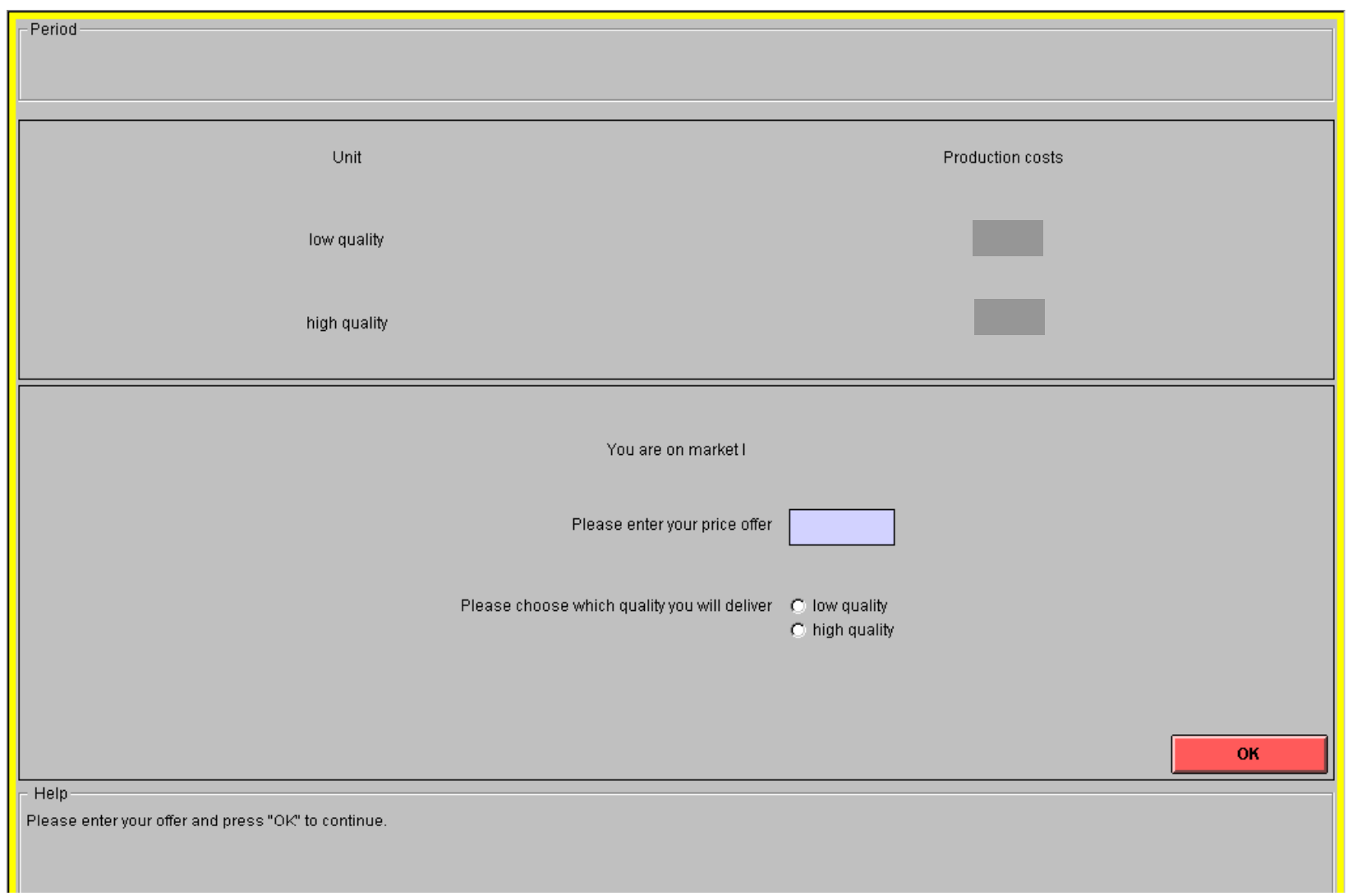


The production costs of high and low quality will be displayed. The seller makes his offer by entering a price and clicking on the quality he delivers if the buyer accepts. By clicking on the o.k.-button he submits his offer to the buyer. After this, the offer can not be revised.

Please note: The buyer will only see the price but not the quality the good. Only upon acceptance does he learn the quality and hence whether the good is of high or low value to him and which income he has earned.

A buyer will see the following screen:

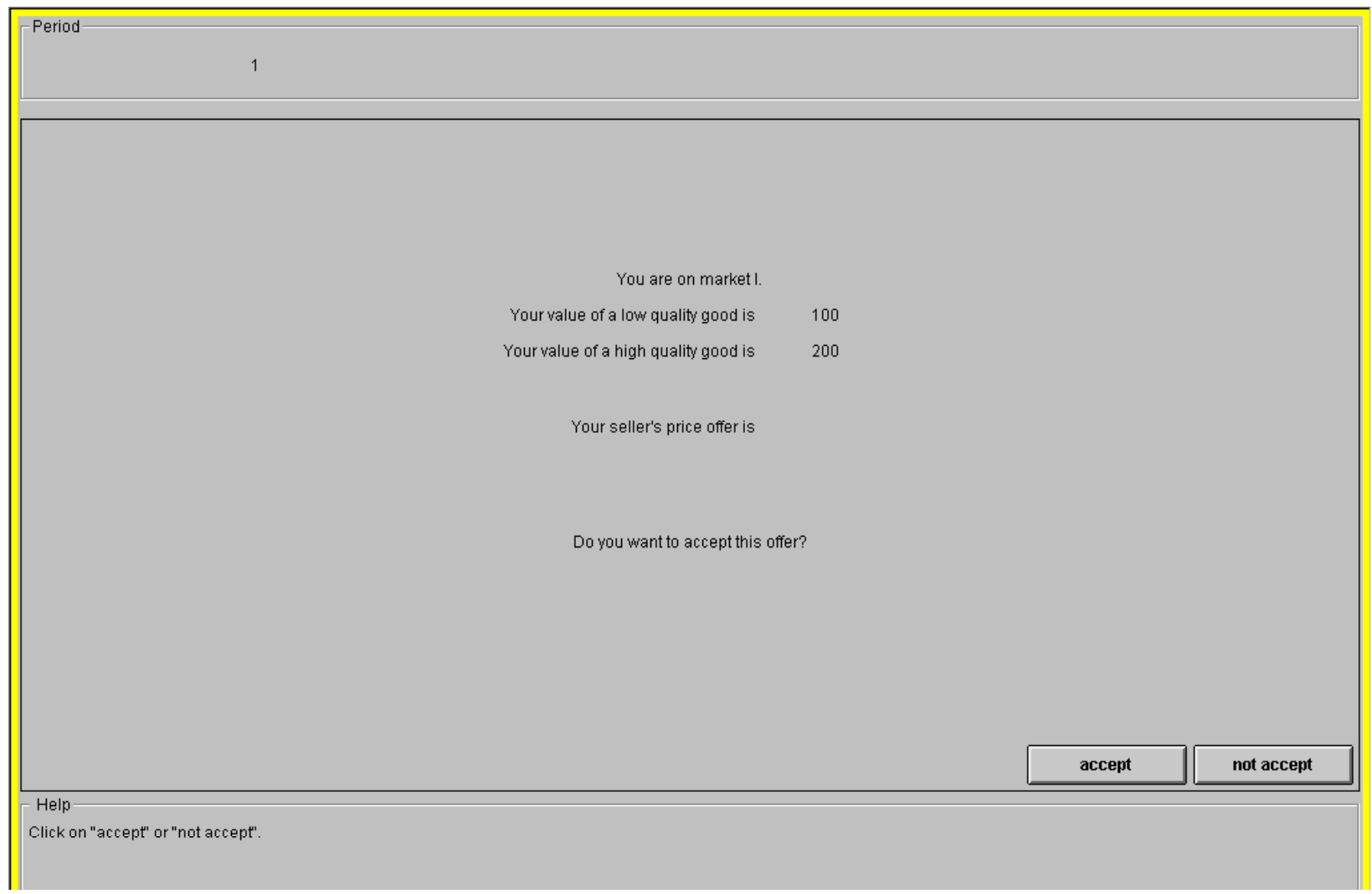

The buyer decides, whether to accept or reject the offer by clicking the corresponding button.

\section{- The buyer accepts the offer}

The buyer will see an income screen with the following information: price; the delivered quality of the good (low or high); the value of the good (100 or 200) and his income for this period (= value - price)

The seller receives an income screen with: the price; his production costs, subject to the quality he has produced; his income in this period (= price - production costs subject to the produced quality).

Only if the buyer has accepted the offer, will both stay on market I, i.e., the seller will submit an offer to the same buyer in the following period.

\section{- The buyer rejects the offer}

After a rejection on market I, both buyer and seller trade on market II. The seller submits a new offer for the current period and the buyer can buy one of the available offers on market II. 


\section{Trading rules on market II}

On market II there are several sellers and several buyers. There are always more sellers than buyers, i.e., even if all buyers accept an offer there will be some sellers, who will not sell their good. Contrary to market I an offer cannot be submitted to a specific buyer and a buyer cannot identify which seller has made a particular offer.

\section{How to submit an offer}

Every seller has to submit an offer in every period by determining a price and the quality of his good.

A seller will see the following input-screen:

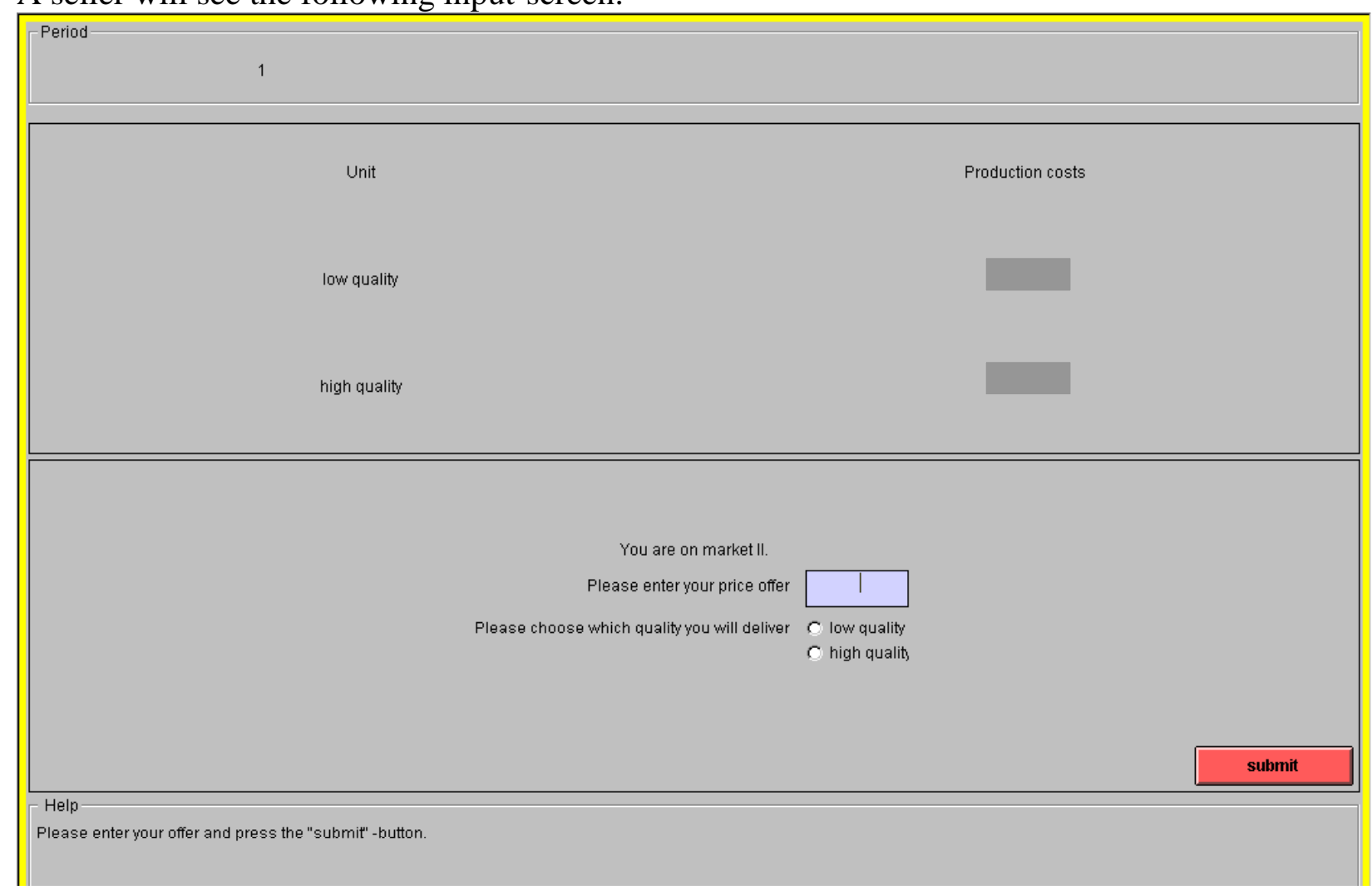

The production costs of a high and low quality good will be displayed. The seller makes his offer by entering a price and clicking on the quality he will produce if a buyer accepts his offer. By clicking on the "submit"-button with the mouse he submits his offer. Once an offer is submitted it cannot be revised.

\section{- The decision of the buyers}

A list of all offers on market II in decreasing order of price will be displayed to buyers on that market. It is not possible to infer which seller has made a specific offer.

Please note: Buyers can only see the prices offered but not, which quality will be delivered. Only on acceptance does a buyer learn the quality of the good he bought and thus whether it has a high or a low value for him and which income he has earned in this trade. 
Buyers will see the following input-screen:

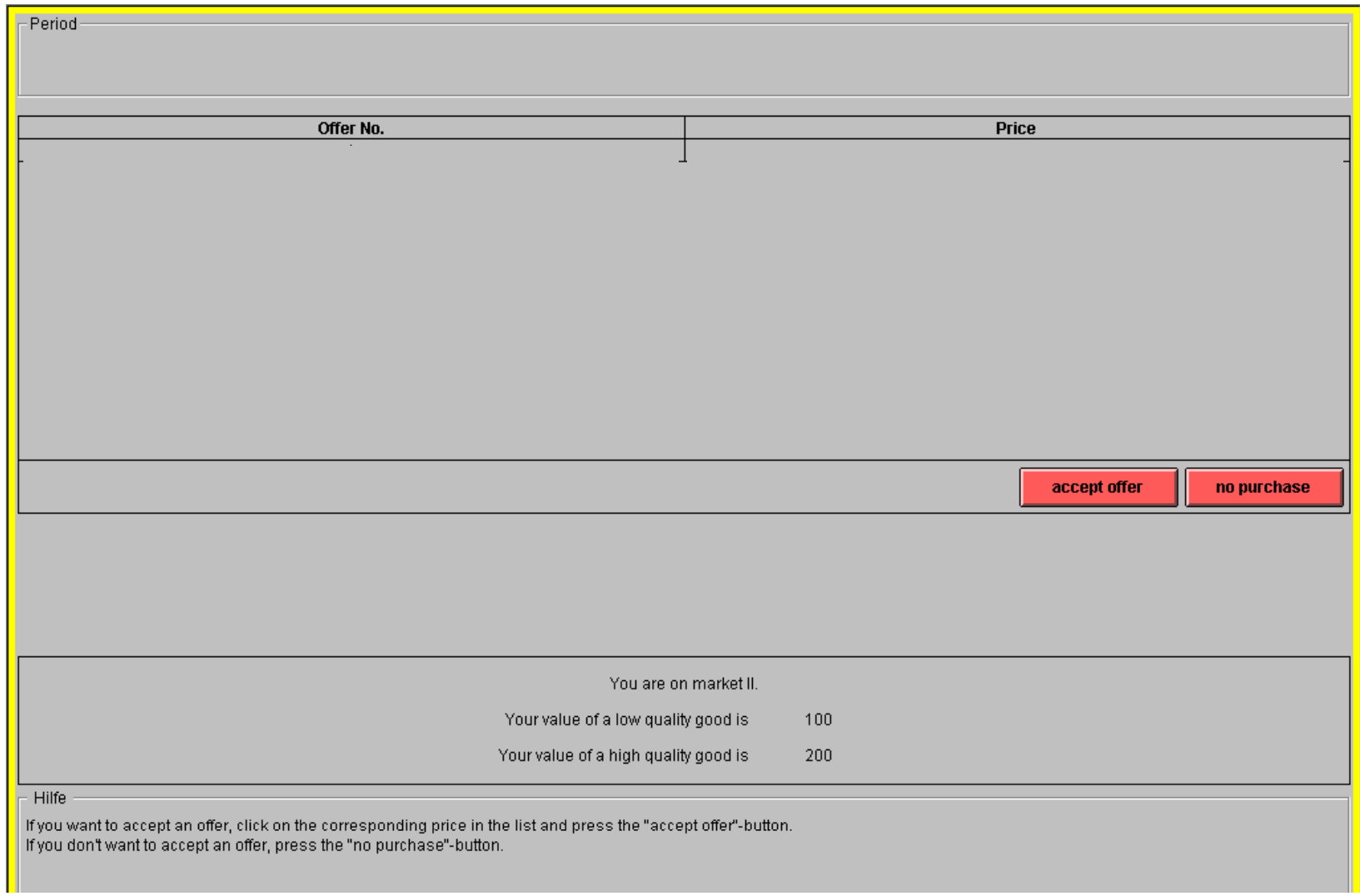

The buyers on market II are asked, one after another, whether they want to accept one of the available offers. A first buyer is randomly chosen. This buyer will see all available offers on market II. If he wants to accept an offer, he clicks on it with the mouse. With another click on the "accept offer"-button the trade is concluded and the offer is removed from the list. If he does not want to buy any offer he clicks on the "no purchase"-button. As soon as the first buyer has finished his decision, the next buyer is randomly chosen. He will see all offers that are still available on market II and decide whether to accept an offer.

Once all buyers have decided they will be informed via an income screen:

whether they have concluded a trade; at which price they have purchased; whether the good is of low or high quality; the value of the good (100 or 200) and the income in this period (= value - price).

Sellers, in turn, are informed via their income screen: whether they have sold their good; their income in this period (= price - production costs subject to the produced quality).

Therewith the trading period is over and a new one starts in which new trades can be concluded. 


\section{Trading phases and access to market I and market II}

There will be several trading phases. Every trading phase consists of 10 trading periods.

When a new phase starts the period counter at the top left of the screen will start again with period 1. In every trading phase some sellers and buyers start on market I. A seller and a buyer stay on market I as a fixed pair, as long as the buyer accepts the seller's offers. As soon as the buyer rejects an offer they both join market II and stay there until the trading phase ends after 10 periods. It is not possible to return to market I. The sellers and buyers who start on market I are randomly chosen and randomly matched.

At the beginning of a new trading phase sellers and buyers are again randomly chosen and matched such that nobody will trade with the same person when starting again on market I.

All sellers and buyers who do not start on market I are on market II for the whole 10 periods of a trading phase. 


\section{Appendix B: Screens announcing the cost shock in period 3}

At the beginning of period 3 the information on the temporary cost increase was shown on the screens below. In the private information treatment (PRIVATE) the following screen was shown to sellers:

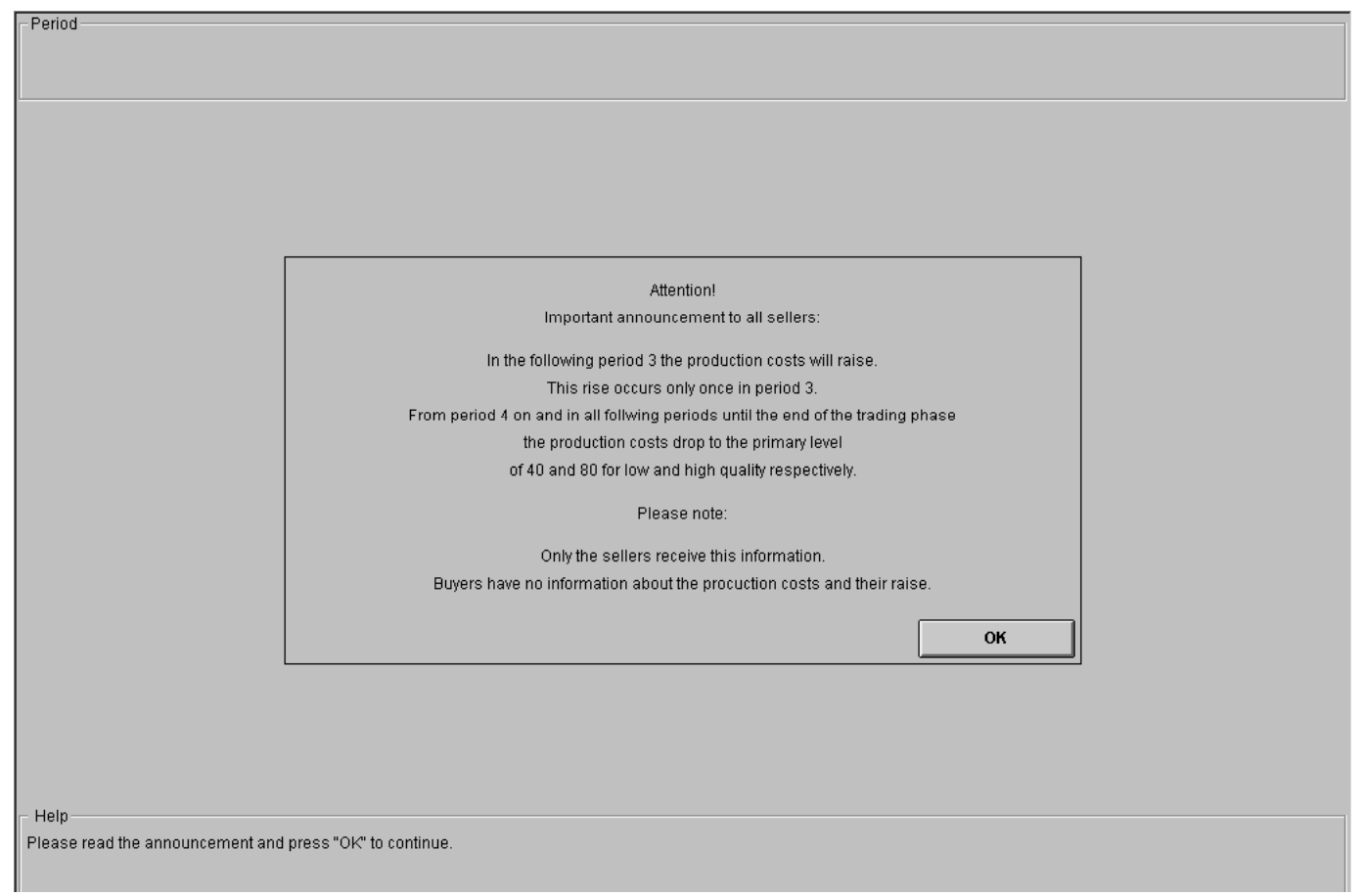

In the public information treatment the screen below was shown to both sellers and buyer.

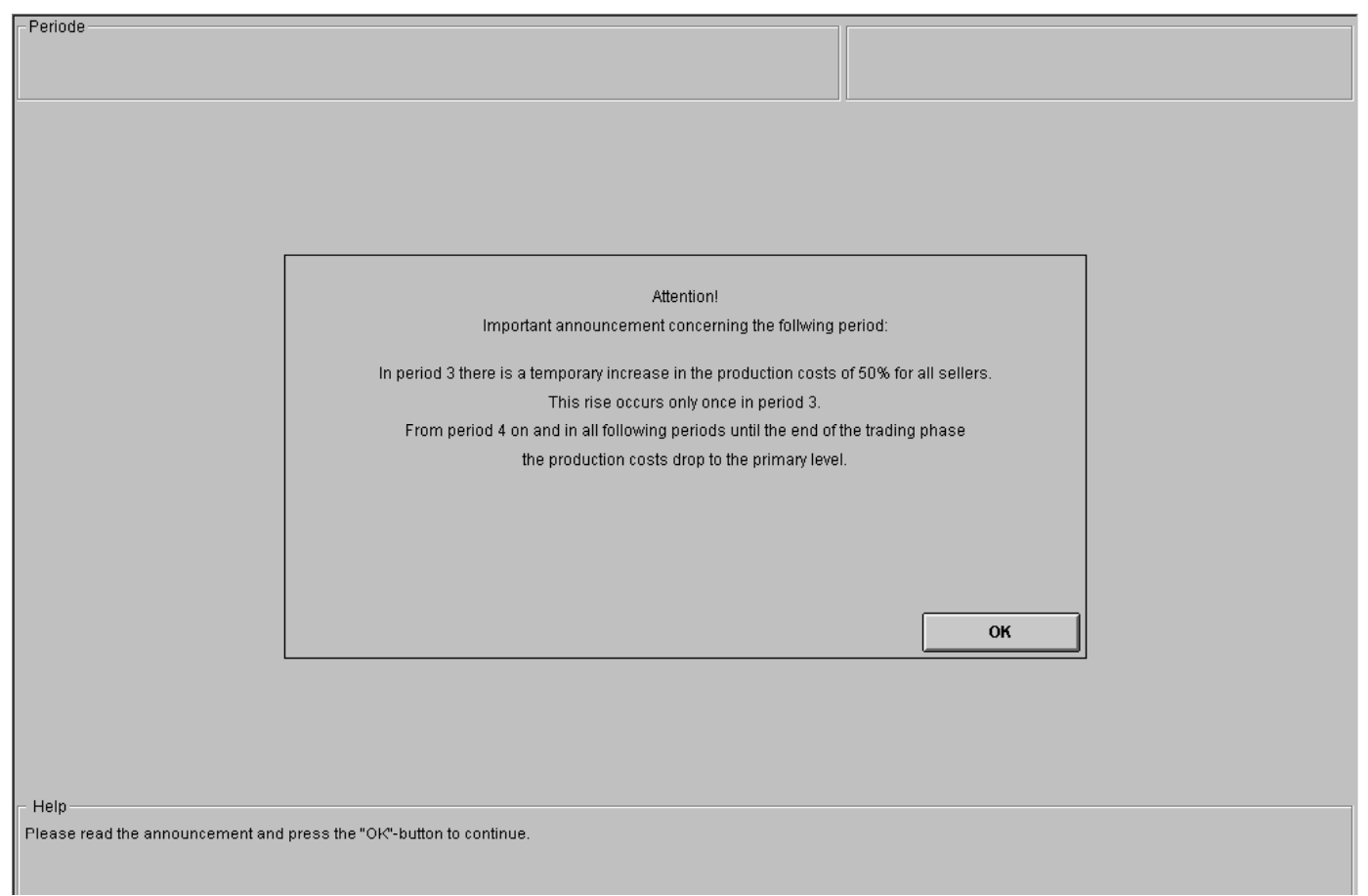


Appendix C: Average transaction prices with public information (upper panel) and private information (lower panel)
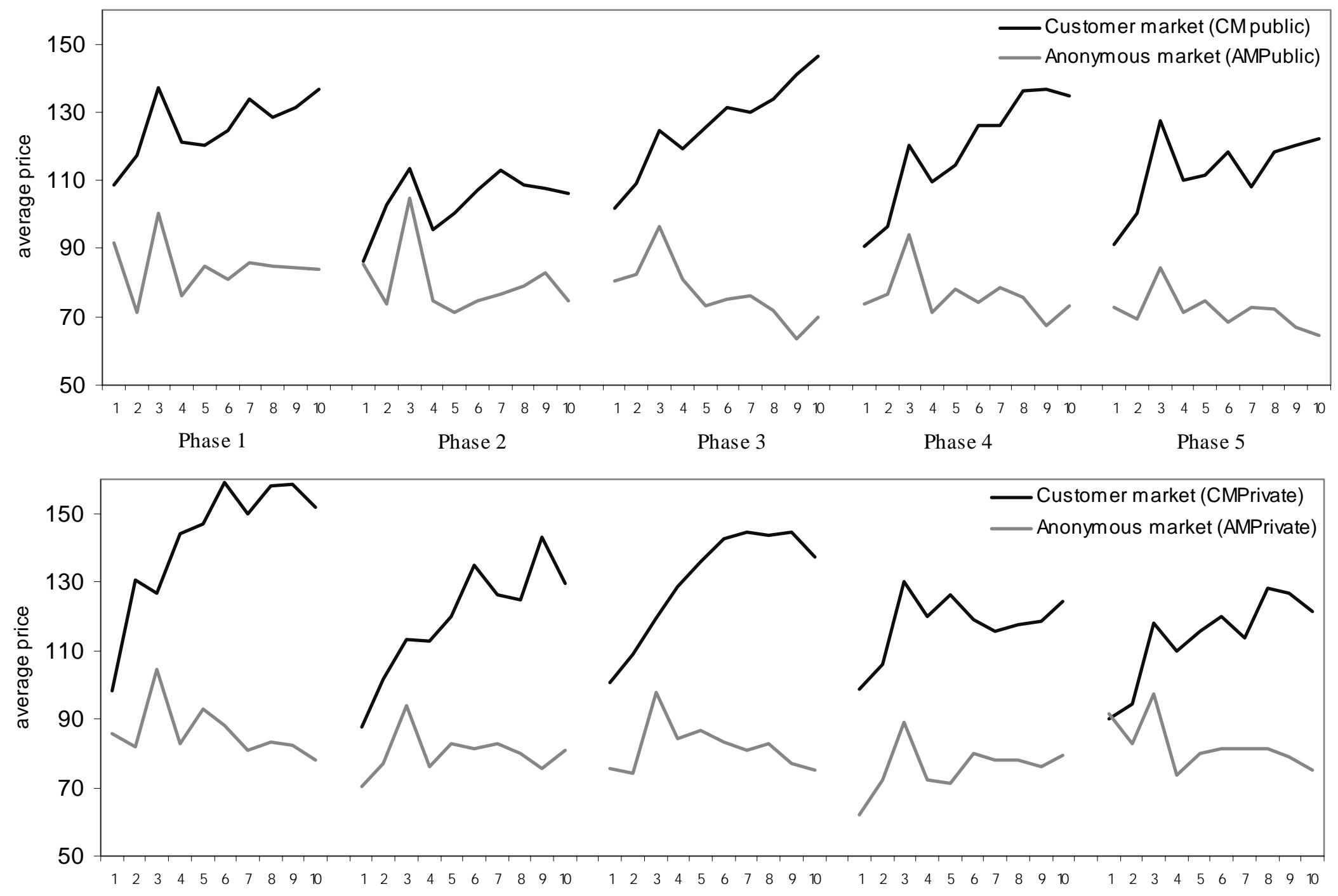